\title{
Kesadaran Mengenai Digital Safety di Kalangan Guru Sekolah Dasar
}

\author{
Roy Ardiansyah, Syafni Nur Afifah, Hasan Mahfud
}

Universitas Sebelas Maret

royardiansyah@staff.uns.ac.id

\section{Article History}

received 3/03/2021

revised 30/03/2021

accepted 3/04/2021

\begin{abstract}
This study aims to examine elementary school teachers' awareness of digital safety. The digital safety in this study are comprised of four competencies as indicator, such as: (1) protecting device; (2) protecting personal data and privacy; (3) protecting health and well-being; (4) protecting environment. This study use mix-method approach, sequential explanatory design, with both quantitative and qualitative data collection. This study is conducted on SD Negeri Mangkubumen Lor No. 15, a public school in Laweyan, Surakarta. The subjects of this study are 20 teachers of SD Negeri Mangkubumen Lor No. 15. Quantitative and qualitative data collection both used to explore teacher's awareness of digital safety through the evidence of their knowledge, attitude and behavior toward digital safety with the use of questionnaire, semi structured interview and secondary data gatheting. The result of this study found that the teachers already have awareness about digital safety in all four indicators of digital safety. However, their guidance regarding student's digital safety still limited only on protecting health and well-being indicator. The finding also implicate that there's a need of continuous improvement and transformation regarding teachers' digital literacy as to welding future digital risk as well as the need of parents' collaboration.
\end{abstract}

Keywords: digital literacy, digital safety, teacher competency, ict

\begin{abstract}
Abstrak
Penelitian ini bertujuan menyelidiki kesadaran guru Sekolah Dasar terkait digital safety (keamanan digital). Digital safety dalam penelitian ini merujuk pada empat kompetensi sebagai indikator, meliputi: (1) perlindungan perangkat; (2) perlindungan data personal dan privasi; (3) perlindungan kesehatan dan kemaslahatan; serta (4) perlindungan lingkungan. Penelitian ini menggunakan pendekatan mix method dengan desain penelitian sequential explanatory. Penelitian dilaksanakan di SD Mangkumen Lor No. 15, Kecamatan Laweyan, Surakarta, dengan subjek penelitian sejumlah 20 guru. Pengumpulan data kuantitatif dan kualitatif digunakan untuk mengeksplorasi kesadaran guru mengenai digital safety yang dilihat dari pengetahuan, sikap dan perilaku guru terhadap keamanan digital dengan menggunakan kuisioner, wawancara semi terstruktur dan pengumpulan data sekunder. Hasil penelitian menemukan bahwa guru sudah memiliki kesadaran tentang digital safety pada keempat indikator. Namun, pembinaan terkait digital safety siswa masih sebatas pada indikator perlindungan kesehatan dan kemasalahatan. Temuan ini mengumplikasikan kebutuhan peningkatan dan transformasi berkelanjutan terkait literasi digital guru untuk mengatasi ancaman digital di masa depan serta kebutuhan akan kolaborasi orang tua.
\end{abstract}

Kata kunci: literasi digital, keamanan digital, kompetensi guru, TIK 


\section{PENDAHULUAN}

Kemajuan IPTEK memicu munculnya tantangan pendidikan baru pada abad 21 . Keberadaan kemajuan IPTEK tersebut menjadikan pembelajaran harus mengalami perubahan paradigma agar dapat menyesuaikan diri dengan tuntutan abad 21. Salah satu tuntutan dalam pendidikan abad 21 adalah moderenisasi bidang pendidikan yaitu berkenaan dengan pengintegrasian teknologi dalam pembelajaran (Kurniawati, Maolida, \& Anjaniputra, 2018; Sonia, 2019). Integrasi teknologi dalam pembelajaran sebenarnya sudah dimulai dari kemunculan e-learning pada tahun 1970-an (Walker \& Wilson, 2001). Kendati demikian, di Indonesia tidak terdapat kewajiban integrasi teknologi dalam pembelajaran sampai dengan adanya kebijakan peralihan pembelajaran konvensional tatap muka dengan pembelajaran daring sejak Maret 2020 berdasarkan Surat Edaran Kemendikbud Nomor 15 Tahun 2020. Kondisi yang demikian menuntut terjadinya integrasi teknologi dalam pembelajaran agar pembelajaran itu sendiri tetap dapat terlaksana. Ketidaksiapan stakeholder pendidikan menghadapi hal tersebut dapat menimbulkan permasalahan. Permasalahan ini dapat berasal dari guru, orang tua, peserta didik atau dari media pembelajaran (Ihwanah, 2020).

Guru menjadi sosok vital dalam menghadapi permasalahan seiring implementasi kewajiban dilaksanakannya pembelajaran daring ini. Guru dianggap sebagai faktor kunci dalam pengintegrasian teknologi dalam pembelajaran (Jannah, Prasojo, \& Jerusalem, 2020). Sayangnya, dalam penelitian sebelumnya ditemukan bahwa guru di beberapa daerah belum dapat melakukan integrasi teknologi dalam pembelajaran sehingga proses adaptasi ke model pembelajaran baru ini tidak serta merta dapat dilakukan (Sumardi, 2020). Berkaitan dengan hal tersebut, terdapat urgensi bagi guru untuk menguasai literasi digital agar dapat melakukan integrasi teknologi dalam pembelajaran dengan baik karena keputusan pengintegrasian teknologi dalam pembelajaran dipengaruhi oleh tingkat literasi digital guru (Mac Callum, Jeffrey, \& NA, 2014).

Literasi digital sendiri merupakan jenis literasi yang dianggap sebagai survival skill abad 21 (Eshet-Alkalai, 2004). Definisi literasi digital tidak hanya mencakup kemampuan untuk mengoperasikan teknologi. Bahkan dalam beberapa framework literasi digital seperti DigCom 2.1, kemampuan teknis yang berkaitan dengan operasional perangkat ini bukan lagi menjadi suatu aspek/ dimensi/ area kompetensi tersendiri (Vuorikari, Punie, Carretero, \& Van Den Brande, 2016). Kemampuan yang melibatkan operasional perangkat baik perangkat keras ini sudah terintegrasi dengan aspek/ area kompetensi lain dalam literasi digital karena dianggap sebagai kemampuan dasar yang menjadi medium dari penerapan literasi digital (lordache, Mariën, \& Baelden, 2017). Interpretasi mengenai literasi digital semakin berkembang sehingga juga memuat komponen kognitif dan sikap sosial (Rambousek, Stipek, \& Vankova, 2016, p. 354). Ferrari (2012) mengemukakan terjadinya pergeseran fokus framework kompetensi digital dengan lebih mempertimbangkan kemampuan berpikir tingkat tinggi dan yang berkaitan dengan keterampilan abad 21 (Ferrari, Punie, \& Redecker, 2012).

Implementasi literasi digital secara umum dan teknologi secara khusus dalam pembelajaran pada dasarnya memiliki banyak keunggulan, misalnya kesesuaian pembelajaran dengan karakteristik peserta didik (yang merupakan generasi Z) yang memang tumbuh dan berkembang bersama teknologi digital itu sendiri (Jannah et al., 2020), tetapi dalam implementasinya menimbulkan beberapa permasalahan. Salah satunya yaitu munculnya ancaman keamanan (digital safety), terutama pada peserta didik yang sudah mengoperasikan perangkat digital sendiri baik dalam pelaksanaan pembelajaran maupun aktivitas sehari-hari. Ancaman tersebut dapat berupa ancaman secara mental, fisik maupun legal (Tomczyk, 2019b), seperti cyberbullying, permasalahan kesehatan serta permasalahan yang dapat bersinggungan dengan 
legalitas hukum. Akses peserta didik pada perangkat digital yang terkoneksi dengan internet menjadikan lebih rentan terhadap resiko dan ancaman digital (Kritzinger, 2017). Berkaitan dengan ini, guru tidak hanya perlu mengantisipasi kemunculan resiko dari situasi yang terjadi secara offline, tetapi juga dari situasi yang terjadi di lingkungan digital di mana pembelajaran daring berlangsung aktivitas sehari-hari peserta didik dalam dunia digital (Tomczyk, 2020). Oleh karena itu, guru harus terlebih dahulu memiliki kesadaran mengenai digital safety, baik dalam yang berkaitan dengan keamanan digital guru itu sendiri atau keamanan digital peserta didik serta pentingnya peserta didik terhadap pemahamanan mengenai strategi keamanan di lingkungan digital.

Guru Sekolah Dasar secara khusus dikatakan memiliki tanggung jawab terkait keamanan digital peserta didik dikarenakan kebiasaan peserta didik pada jenjang masih cenderung lebih mudah dipengaruhi sehingga guru lebih mudah membekali peserta didik agar dapat melindungi diri di lingkungan digital (Tomczyk, 2019a). Pada jenjang Sekolah Dasar khususnya kelas tinggi (kelas 4, kelas 5 dan kelas 6) di mana peserta didik sudah mulai mengoperasikan perangkat digital sendiri baik dalam pelaksanaan pembelajaran maupun aktivitas sehari-hari, ancaman terkait digital safety perlu mendapatkan perhatian lebih lanjut. Berkaitan dengan hal tersebut, perlu penekanan pemahaman guru mengenai kesadaran akan digital safety perlu menjadi menjadi penyelidikan lebih lanjut.

Digital safety ini juga merupakan salah satu area kompetensi dalam framework literasi digital seperti DigCom dan Digital Literacy Global Framework (Carretero, Vuorikari, \& Punie, 2017; UNESCO, 2018). Berdasarkan framework literasi digital DigCom 2.1, digital safety dalam penelitian ini merujuk pada pada area kompetensi keamanan (safety) yang mana terdiri atas 4 kompetensi sebagai indikator yaitu: (1) protecting devices (perlindungan perangkat; (2) protecting personal data and privacy (perlindungan data personal dan privasi); (3) protecting health and well-being (perlindungan kesehatan dan kemasalahatan); dan (4) protecting the environment (perlindungan lingkungan) (Carretero et al., 2017). Masih jarang dilakukan penelitian mengenai digital safety dengan subjek guru, terutama guru Sekolah Dasar (Tomczyk, 2019b, 2019a). Penelitian-penelitian sebelumnya mengenai literasi digital guru yang juga melibatkan aspek safety sebagai salah satu area kompetensi di dalamnya kurang begitu membahas area kompetensi tersebut secara khusus (Abdulteeef \& Khateeb, 2017; Rizal, Setiawan, \& Rusdiana, 2019), sehingga digital safety menjadi topik yang patut dikaji lebih lanjut. Berdasarkan hal tersebut, penelitian ini bertujuan menyelidiki mengenai kesadaran guru SD mengenai digital safety.

\section{METODE}

Penelitian ini menggunakan pendekatan mix-method dengan desain penelitian sequential explanatory design untuk menggali mengenai kesadaran guru mengenai digital safety dari pengumpulan data kuantitatif yang diperjelas dengan pengumpulan data kualitatif secara sekuential. Penelitian dilakukan di SD Negeri Mangkubumen Lor No. 15 Kecamatan Laweyan, Kota Surakarta pada November-Desember 2020. Subjek penelitian yaitu 20 guru. Penelitian dilakukan dengan pengambilan data kuantitatif dan kuantitatif. Pengambilan data kuantitatif dilakukan kuisioner dan teknik pengambilan sampel quota sampling, yaitu pengambilan data dengan kuota yang ditetapkan. Analisis data tahapan ini yaitu analisis deskriptif kuantitatif.

Pengambilan sampel tahapan kuantitatif dilakukan dengan wawancara mengenai sikap dan perilaku guru terkait digital safety serta studi dokumentasi yang relevan terhadap praktik digital safety yang dilakukan guru. Pengambilan sample untuk pengumpulan data kualitatif dilakukan dengan teknik purposive sampling dengan sampel penelitian sejumlah 3 guru yang mana masing-masing mengajar kelas 4, 5 dan 6. Uji keabsahan data dilakukan dengan triangulasi sumber. Data hasil kuisioner 
dianalisis dengan statistic deskriptif sementara data hasil wawancara dan studi dokumentasi dianalisis dengan analisis interaktif (Miles, Huberman, \& Saldaña, 2014) dalam menganalisis data penelitian. Level profisiensi literasi digital dinilai berdasarkan tabel 1 berikut.

Tabel 1. Level Profisiensi Literasi Digital

\begin{tabular}{|c|c|c|c|c|}
\hline $\begin{array}{l}\text { Level } \\
\text { (DigCom } \\
1.0)\end{array}$ & $\begin{array}{l}\text { Level } \\
\text { (DigCo } \\
\text { m 2.0) }\end{array}$ & Complexity of Task & Autonomy & $\begin{array}{l}\text { Cognitive } \\
\text { Domain }\end{array}$ \\
\hline Foundation & $\begin{array}{l}1 \\
2\end{array}$ & $\begin{array}{l}\text { Simple tasks } \\
\text { Simple tasks }\end{array}$ & $\begin{array}{l}\text { With guidance } \\
\text { Autonomy and } \\
\text { with guidance } \\
\text { where needed }\end{array}$ & $\begin{array}{l}\text { Remembering } \\
\text { Remembering }\end{array}$ \\
\hline \multirow[t]{2}{*}{ Intermediate } & 3 & $\begin{array}{l}\text { Well-defined and } \\
\text { routine tasks, and } \\
\text { straightforward } \\
\text { problems }\end{array}$ & On my own & Understanding \\
\hline & 4 & $\begin{array}{l}\text { Tasks, and well-defined } \\
\text { and non-routine } \\
\text { problems }\end{array}$ & $\begin{array}{l}\text { Independent } \\
\text { and according } \\
\text { to my needs }\end{array}$ & Understanding \\
\hline \multirow[b]{2}{*}{ Advanced } & 5 & $\begin{array}{l}\text { Different tasks and } \\
\text { problems }\end{array}$ & Guiding others & Applying \\
\hline & 6 & Most appropriate tasks & $\begin{array}{l}\text { Able to adapt } \\
\text { to others in a } \\
\text { complex } \\
\text { context }\end{array}$ & Evaluating \\
\hline \multirow[t]{2}{*}{$\begin{array}{c}\text { Highly } \\
\text { Specialized }\end{array}$} & 7 & $\begin{array}{l}\text { Resolve complex } \\
\text { problems with limited } \\
\text { solutions }\end{array}$ & $\begin{array}{l}\text { Integrate to } \\
\text { contribute to } \\
\text { the } \\
\text { professional } \\
\text { practice and to } \\
\text { guide others }\end{array}$ & Creating \\
\hline & 8 & $\begin{array}{l}\text { Resolve complex } \\
\text { problems with many } \\
\text { interacting factors }\end{array}$ & $\begin{array}{l}\text { Propose new } \\
\text { ideas and } \\
\text { processes to } \\
\text { the field }\end{array}$ & Creating \\
\hline
\end{tabular}

Sumber: (Carretero et al., 2017)

HASIL DAN PEMBAHASAN

Hasil kuisioner penelitian mengenai literasi digital area kompetensi keamanan (digital safety) yang diberikan kepada 20 guru SD Negeri Mangkubumen Lor No. 15 dapat dilihat pada gambar 1 berikut. 


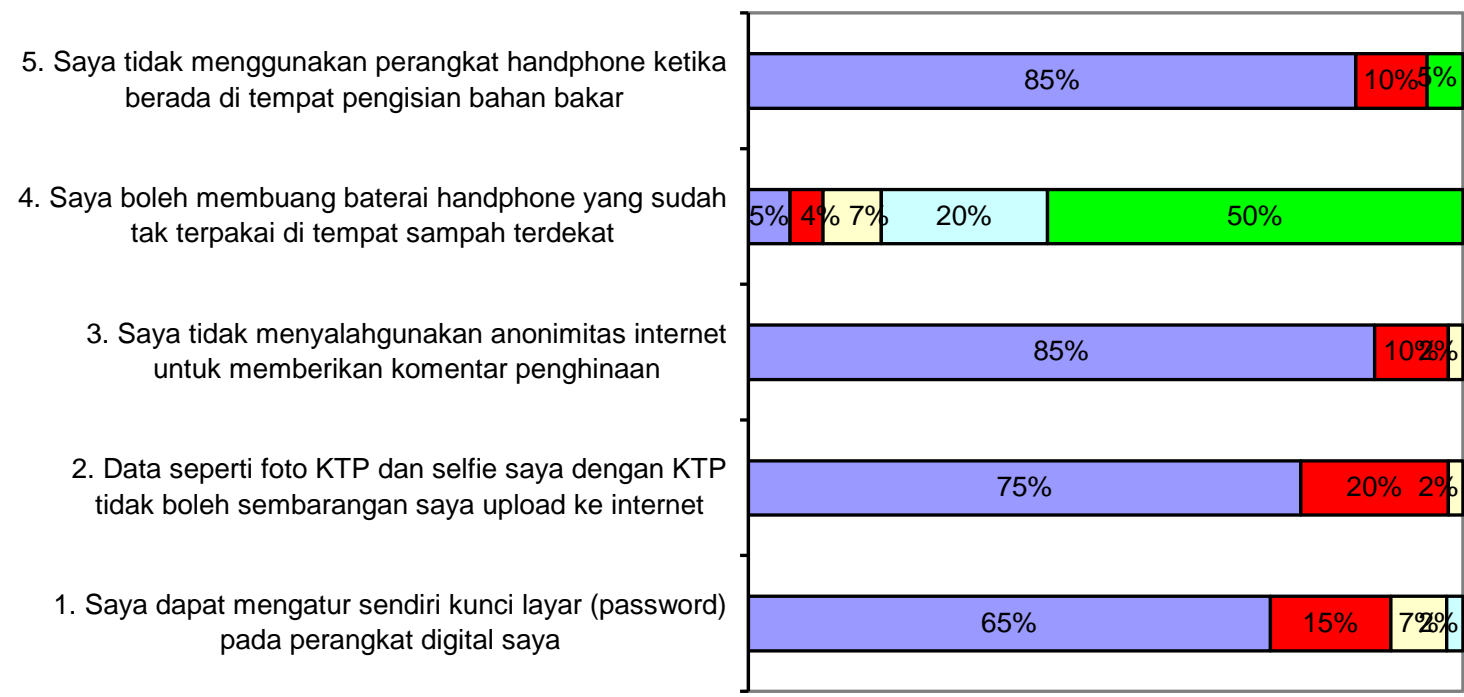

$\square$ Sangat Setuju $\square$ Setuju $\square$ Netral $\square$ Tidak Setuju $\square$ Sangat Tidak Setuju

\section{Gambar 1. Hasil Kuisioner Literasi Digital Area Kompetesi Keamanan Guru SD Negeri Mangkubumen Lor No. 15}

Pernyataan 1, 2, 3 dan 5 pada kuisioner merupakan pernyataan yang mengindikasikan sikap positif terhadap digital safety sementara untuk pernyataan 4 merupakan pernyataan negatif. Berdasarkan gambar 1 tersebut dapat diperhatikan bahwa untuk mayoritas guru sangat menyetujui atau menyetujui pernyataan positif berkaitan dengan digital safety, sementara mayoritas guru sangat tidak menyetujui atau tidak menyetujui pernyataan negatif berkaitan dengan digital safety. Berdasarkan hal tersebut dapat disimpulkan bahwa guru setidaknya telah memiliki sikap dan perilaku positif serta pengetahuan dasar berkaitan dengan digital safety.

Berdasarkan hasil dari kuisioner, dipilih 3 guru yang dapat mewakili keseluruhan subjek untuk menyelidiki lebih lanjut kesadaran guru terhadap digital safety melalui wawancara dan studi dokumentasi. Dokumentasi yang diperoleh yaitu berupa chat grup kelas dalam aplikasi WhatsApp serta screenshoot akun e-mail dan Google Drive yang dimiliki guru. Rangkuman hasil wawancara dan studi dokumentasi ini dapat dilihat pada tabel 2 berikut.

Tabel 2. Pengetahuan, Perilaku dan Sikap Guru berkaitan dengan Digital Safety

\begin{tabular}{|c|c|c|}
\hline Indikator & Pengetahuan, Perilaku atau Sikap & $\begin{array}{c}\text { Level } \\
\text { Profisiensi }\end{array}$ \\
\hline $\begin{array}{l}\text { Perlindungan } \\
\text { perangkat }\end{array}$ & $\begin{array}{l}\text { - Mengerti dan kadang melakukan pemasangan } \\
\text { - Mandi pada HP atau laptop } \\
\text { Mengerti dan kadang melakukan pemasangan } \\
\text { aksesoris perlindungan tambahan seperti } \\
\text { casing dan temper glass pada HP } \\
\text { - Melindungi infomasi, data, konten pada platform } \\
\text { Google Drive dan Google Classroom dengan } \\
\text { memasang sandi pada e-mail }\end{array}$ & $\begin{array}{c}4 \\
\text { (Intermediate) }\end{array}$ \\
\hline $\begin{array}{l}\text { Perlindungan } \\
\text { data personal } \\
\text { dan privasi }\end{array}$ & $\begin{array}{l}\text { - Memilah sedemikian rupa konten yang } \\
\text { dibagikan agar hanya berkaitan dengan } \\
\text { pembelajaran atau hal di luar tersebut yang } \\
\text { tidak menyangkut data personal dan privasi }\end{array}$ & $\begin{array}{c}6 \\
\text { (Advanced) }\end{array}$ \\
\hline
\end{tabular}




\begin{tabular}{|c|c|c|}
\hline & $\begin{array}{l}\text { - Menghindari pemakaian fitur tertentu dalam } \\
\text { suatu platform, misalnya fitur status dalam } \\
\text { aplikasi WhatsApp untuk menjaga kerahasiaan } \\
\text { kehidupan personal }\end{array}$ & \\
\hline $\begin{array}{l}\text { Perlindungan } \\
\text { kesehatan dan } \\
\text { kemaslahatan }\end{array}$ & $\begin{array}{l}\text { - Memberi peringkatan mengenai ancaman } \\
\text { kesehatan fisik yang timbul dari pemakaian } \\
\text { perangkat digital secara berlebihan } \\
\text { - Menciptakan suasana kondusif dan } \\
\text { pemantauan aktivitas peserta didik dalam } \\
\text { lingkungan belajar digital seperti Grup Kelas } \\
\text { pada WhatsApp dan ketika pertemuan virtual } \\
\text { melalui Google Meet }\end{array}$ & $\begin{array}{c}7 \\
\text { (Highly } \\
\text { specialized) }\end{array}$ \\
\hline $\begin{array}{l}\text { Perlindungan } \\
\text { lingkungan }\end{array}$ & $\begin{array}{l}\text { - Menyadari mengenai dampak negatif teknologi } \\
\text { digital terhadap lingkungan, terutama } \\
\text { lingkungan sosial } \\
\text { - Memperlihatkan usaha meminimalisir dampak } \\
\text { negatif teknologi terhadap lingkungan sosial } \\
\text { dari diri sendiri }\end{array}$ & $\begin{array}{c}3 \\
\text { (Intermediate) }\end{array}$ \\
\hline
\end{tabular}

Berdasarkan tabel 2 tersebut, guru pada dasarnya sudah memiliki kesadaran berkaitan dengan perlindungan perangkat dengan level profisiensi 4 (Intermediate). Perilaku yang dilakukan guru berkaitan dengan ini dilakukan secara independen dan berdasarkan kebutuhannya akan tetapi guru menunjukkan indikasi dapat membimbing orang lain khususnya peserta didik berkaitan dengan hal ini. Guru juga memiliki kesadaran berkaitan dengan perlindungan data personal dan privasi dengan level profisiensi 6 (advanced). Meskipun belum terdapat indikasi bahwa guru dapat membimbing siswa berkaitan dengan indikator ini, guru telah dapat menyesuaikan mengenai konten digital yang di-post sesuai konteks audience yang dapat melihatnya.

Guru sudah memiliki kesadaran berkaitan dengan perlindungan kesehatan dan kemaslahatan berkenaan dengan perkembangan dunia digital dengan level profisiensi 7 (highly specialized). Guru sudah dapat memberikan arahan dan bimbingan kepada peserta didik mengenai resiko perangkat digital pada kesehatan dan kemaslahatan. Dalam konteks kelas secara terbatas, guru juga sudah menciptakan suasana kondusif dalam lingkungan belajar digital peserta didik, yaitu dengan membebaskan peserta didik berekspresi dan saling berinteraksi dalam kelas digital seperti Grup Kelas pada WhatsApp dan ketika pertemuan virtual melalui Google Meet tetapi tetap melakukan pemantauan terhadap sikap peserta didik sehingga tidak terjadi cyberbullying atau perilaku yang kelewat batas.

Guru juga sudah menyadari mengenai dampak negatif teknologi digital terhadap lingkungan, dengan level profisiensi 3 (intermediate). Meskipun guru mengerti dampak terhadap lingkungan secara fisik, guru menyatakan bahwa dampak tersebut terkesan minimum dibandingkan dampak secara sosial. Meskipun telah menunjukkan pemahaman serta usaha untuk meminimalisir dampak negatifnya, guru baru menerapkan ke dirinya sendiri misalnya dengan membatasi penggunaan perangkat ponsel ketika ketika keluar rumah untuk melakukan pertemuan sosial.

Berdasarkan uraian di atas, guru pada dasarnya telah memiliki kesadaran terhadap isu digital safety secara umum, tetapi mengalami beberapa hambatan terkait melakukan pembinaan kepada siswa mengenai hal tersebut. Guru memiliki pemahaman dan telah menerapkan secara terbatas mengenai strategi perlindungan perangkat. Penerapan terbatas ini dikarenakan guru memiliki prioritas lain seperti praktikalitas yang menyebabkannya kurang melakukan penerapan secara maksimal. Misalnya, ditunjukkan dengan guru yang melakukan penyimpanan berbagai data 
menggunakan Google Drive yang terhubung ke beberapa e-mail dengan kata sandi yang sama agar mudah diingat. Guru tidak merasa perlunya penggunaan kata sandi yang unik karena tidak mempertimbangkan peretasan data. Padahal peretasan bisa terjadi pada siapa saja dan tidak terdapat jaminan bahwa e-mail pembelajaran guru tersebut aman (Noor, 2020). Data yang berhubungan dengan pembelajaran adalah data yang penting sehingga guru perlu melakukan pengelolaan yang mempertimbangkan keamanan.

Guru juga menunjukkan pemahaman terhadap strategi perlindungan data personal dan privasi. Berkaitan dengan hal ini, guru sudah memiliki kesadaran akan siapa yang dapat mengakses konten yang dibagikan melalui platform media sosial (awareness of audience) yang mana ini juga berkaitan dengan pengelolaan identitas digital. Hal ini juga merupakan hal yang penting untuk menjaga reputasi guru (lordache et al., 2017). Guru seharusnya juga menanamkan mengenai awareness of audience ini kepada peserta didik mengingat semakin meningkatnya penggunaan jejaring sosial oleh peserta didik.

Digital Safety pada dasarnya salah satu area kompetensi literasi digital yang patut menjadi perhatian mengingat munculnya ancaman-ancaman digital baru seiring dengan perkembangan teknologi digital. Ancaman-ancaman ini akan mengalami perkembangan seiring dengan perkembangan teknologi itu sendiri. Isu mengenai digital safety ini kerap kali diserahkan pada guru atau sekolah (Tomczyk, 2019a). Berkaitan dengan hal ini, guru harus menghadapi tantangan perubahan yang terus menerus tersebut dan terus memperbaharui kemampuan literasi digitalnya secara umum dan kesadaran akan digital safety secara khusus (Creer \& Adelecreerucmacim, 2018; Tomczyk, 2019b). Hal ini sesuai dengan prinsip pembelajaran seumur hidup dalam pengembangan professional guru yang berkelanjutan (Mukan, Yaremko, Kozlovskiy, Ortynskiy, \& Isayeva, 2019).

Dürager \& Sonck (2014) mengidentifikasi 5 strategi utama dalam mediasi penggunaan internet dan media digital yang meliputi mediasi aktif penggunaan internet, mediasi aktif keamanan penggunaan internet, mediasi restriktif, pembatasan teknis, serta pemantauan. Meskipun konteks penelitian tersebut merupakan mediasi yang dilakukan oleh orang tua, hal tersebut dapat diterapkan pada konteks mediasi yang dilakukan guru berkaitan dengan digital safety ini. Berdasarkan hasil penelitian ini, terlihat bahwa guru sudah melakukan upaya mediasi aktif terkait kemanan digital serta pemantauan terbatas dalam indikator perlindungan kesehatan, sementara untuk indikator lainnya belum dapat dilakukan dikarenakan beberapa kendala.

Guru mengeluhkan kendala waktu sebagai alasan kurang efektifnya pemantauan aktivitas digital siswa yang kurang berhubungan dengan pembelajaran. Praktik pembelajaran yang dilakukan di Sekolah Dasar selama pandemic Covid-19 sering kali tidak hanya merupakan pembelajaran dalam jaringan saja, tetapi juga melibatkan praktik pembelajaran homevisit yang porsinya menyesuaian tingkatan kelas. Berkaitan dengan hal tersebut, guru mengeluhkan keterbatasan waktu dikarenakan proses penyusunan bahan ajar serta proses pembelajaran sendiri sudah menyita waktu sehingga kurang sempat memantau aktivitas media sosial peserta didik. Berdasarkan penelitian Husni \& Fatulloh (2016) mengenai pengguna internet pada anak usia SD sampai dengan SMP, penggunaan internet sudah dimulai sejak anak usia SD dengan mayoritas pada kelas 3 serta dan penggunaannya mayoritas untuk keperluan akademik, hiburan dan jejaring sosial. Hal ini juga ditambah dengan keberadaan pembelajaran daring yang mana beberapa siswa mengakses sendiri perangkat digital untuk pembelajaran. Semakin meningkatnya perilaku penggunaan internet secara khusus dan perangkat digital secara umum menjadikan pembinaan terkait digital safety pada peserta didik menjadi urgensi yang perlu segera dilaksanakan.

Tidak seluruh permasalahan dapat diselesaikan oleh guru atau sekolah sendiri. Baik itu penyelenggaran lingkungan digital yang kondusif maupun pengembanagan 
kemampuan menghadapi ancaman digital membutuhkan kolaborasi dari seluruh anggota komunitas pembelajaran sehingga perlu adanya kolaborasi antara pihak guru dengan orang tua berkaitan dengan hal ini sehingga tercipta kesadaran mengenai digital safety pada peserta didik dan lingkungan digital yang aman (Mark \& Nguyen, 2017).

\section{SIMPULAN}

Guru pada dasarnya telah memiliki kesadaran terkait digital safety ditinjau dari kompetensi perlindungan perangkat perlindungan data personal dan privasi, perlindungan kesehatan dan kemasalahatan serta perlindungan lingkungan, tetapi kesadaran tersebut cenderung lebih terbatas kepada pemahaman dan kemampuan mengimplementasikannya. Hanya dalam kompetensi perlindungan kesehatan, guru juga memiliki kesadaran untuk menyampaikan strategi perlindungan kesehatan fisik berkaitan dengan perangkat digital dan berupaya menciptakan lingkungan belajar digital yang kondusif bagi kesehatan mental peserta didik.

Dapat diimplikasikan bahwa seiring dengan perkembangan teknologi digital, ancaman digital hanya akan terus bertambah, sehingga perlu peningkatan dan pembaharuan berkelanjutan kemampuan literasi digital guru sesuai dengan prinsip pembelajaran seumur hidup dalam pengembangan profesional guru (Mukan et al., 2019). Selain itu, berkaitan dengan pengembangan literasi digital peserta didik, pihak sekolah hendaknya melibatkan pihak orang tua melalui proses kolaborasi.

\section{DAFTAR PUSTAKA}

Abdulteeef, A., \& Khateeb, M. Al. (2017). Measuring Digital Competence and ICT Literacy: An Exploratory Study of In-Service English Language Teachers in the Context of Saudi Arabia. International Education Studies, 10(12), 38-51. https://doi.org/10.5539/ies.v10n12p38

Carretero, S., Vuorikari, R., \& Punie, Y. (2017). DigComp 2.1: The Digital Competence Framework for Citizens. With eight proficiency levels and examples of use. In Publications Office of the European Union. Retrieved from http://publications.jrc.ec.europa.eu/repository/bitstream/JRC106281/webdigcomp2.1pdf_(online).pdf

Creer, A., \& Adelecreerucmacim, I. M. (2018). Introducing Everyday “Digital Literacy Practices" into the Classroom: An Analysis of Multi-layered Media, Modes and their Affordances. Journal of New Approaches in Educational Research, 7(2), 131-139. https://doi.org/10.7821/naer.2018.7.265

Dürager, A., \& Sonck, N. (2014). Testing the reliability of scales on parental internet mediation. London: EU Kids Online, LSE.

Eshet-Alkalai, Y. (2004). Digital Literacy: A Conceptual Framework for Survival Skills in the Digital Era. Journal of Educational Multimedia and Hypermedia, 13(1), 93106.

Ferrari, A., Punie, Y., \& Redecker, C. (2012). Understanding Digital Competence in the 21st Century: An Analysis of Current Frameworks. https://doi.org/10.1007/978-3642-33263-0_7

Husni, E. M., \& Fatulloh, A. (2016). Kategorisasi Pengguna Internet di Kalangan Pelajar SD dan SMP Menggunakan Metode Twostep Cluster. Seminar Nasional Aplikasi Teknologi Informasi, 6-16. Retrieved from https://journal.uii.ac.id/Snati/article/view/6256

Ihwanah, A. (2020). Problematika Pembelajaran Daring di Sekolah Dasar pada Era Pandemi Covid-19. JIEES: Journal of Islamic Education at Elementary School, 1(2).

lordache, C., Mariën, I., \& Baelden, D. (2017). Developing digital skills and competences: A quick-scan analysis of 13 digital literacy models. Italian Journal of 
Sociology of Education, 9(1), 6-30. https://doi.org/10.14658/pupj-ijse-2017-1-2 Jannah, M., Prasojo, L. D., \& Jerusalem, M. A. (2020). Elementary School Teachers ' Perceptions of Digital Technology Based Learning in the 21st Century: Promoting Digital Technology as the Proponent Learning Tools. Al Ibtida: Jurnal Pendidikan Guru MI, 7(1), 1-18.

Kritzinger, E. (2017). Growing a cyber-safety culture amongst school learners in South Africa through gaming. South African Computer Journal, 29(2), 16-35. https://doi.org/10.18489/sacj.v29i2.471

Kurniawati, N., Maolida, E. H., \& Anjaniputra, A. G. (2018). The praxis of digital literacy in the EFL classroom: Digital-immigrant vs digital-native teacher. Indonesian Journal of Applied Linguistics, 8(1), 28-37. https://doi.org/10.17509/ijal.v8i1.11459

Mac Callum, K., Jeffrey, L., \& NA, K. (2014). Factors Impacting Teachers' Adoption of Mobile Learning. Journal of Information Technology Education: Research, 13, 141-162. https://doi.org/10.28945/1970

Mark, L. K., \& Nguyen, T. T. T. (2017). An Invitation to Internet Safety and Ethics: School and family collaboration. Journal of Invitational Theory and Practice, 23, 62-75.

Miles, M. B., Huberman, M. A., \& Saldaña, J. (2014). Qualitative Data Analysis: A Methods Sourcebook (3rd Editio). Aizona: SAGE Publications.

Mukan, N., Yaremko, H., Kozlovskiy, Y., Ortynskiy, V., \& Isayeva, O. (2019). Teachers' Continuous Professional Development: Australian Experience. Advanced Education, 6(12), 105-113. https://doi.org/10.20535/2410-8286.166606

Noor, M. U. (2020). Hubungan Tingkat Pendidikan Generasi Milenial Terhadap Upaya Perlindungan Privasi Dan Data Pribadi Di Internet. BIBLIOTIKA : Jurnal Kajian Perpustakaan Dan Informasi, 4(2), 154-163.

Rambousek, V., Stipek, J., \& Vankova, P. (2016). Contents of digital literacy from the perspective of teachers and pupils. Procedia - Social and Behavioral Sciences, 217, 354-362. https://doi.org/10.1016/j.sbspro.2016.02.101

Rizal, R., Setiawan, W., \& Rusdiana, D. (2019). Digital literacy of preservice science teacher. Journal of Physics: Conference Series, 1157(2), 1-6. https://doi.org/10.1088/1742-6596/1157/2/022058

Sonia, T. N. (2019). Menjadi Guru Abad 21: Jawaban Tantangan Pembelajaran Revolusi Industri 4.0. Prosiding Seminar Nasional Teknologi Pendidikan Pascasarjana UNIMED, 191-199. Retrieved from http://digilib.unimed.ac.id/38729/

Sumardi, L. (2020). Does the Teaching and Learning Process in Primary Schools Correspond to the Characteristics of the 21st Century Learning ? International Journal of Instruction, 13(3), 357-370.

Tomczyk, Ł. (2019a). Digital literacy in the area of e-safety among teachers (second stage of the primary school) in Poland. ELearning and Software for Education Conference, 130-135. https://doi.org/10.12753/2066-026X-19-087

Tomczyk, Ł. (2019b). What Do Teachers Know About Digital Safety? Computers in the Schools, 36(3), 167-187. https://doi.org/10.1080/07380569.2019.1642728

Tomczyk, Ł. (2020). Skills in the area of digital safety as a key component of digital literacy among teachers. Education and Information Technologies, 25(1), 471486. https://doi.org/10.1007/s10639-019-09980-6

UNESCO. (2018). A Global Framework of Reference on Digital Literacy. In Information Paper (No. 51).

Vuorikari, R., Punie, Y., Carretero, S., \& Van Den Brande, L. (2016). DigComp 2.0: The Digital Competence Framework for Citizens. In Jrc-lpts. https://doi.org/10.2791/11517

Walker, V., \& Wilson, J. (2001, October). Definition for “E-Learning”"'. Retrieved January 18, 2021, from Newsletter of Open and Distance Learning Quality Control website: https://www.odlqc.org.uk/odlqc/n19-e.html 